\title{
Avaliação de material didático digital centrada no usuário: uma investigação de instrumentos passíveis de utilização por professores
}

Katia Alexandra de Godoi UFPR

Stephania Padovani UFPR

RESUMO

Neste artigo, discute-se a importância da avaliação de materiais didáticos digitais centrada no usuário. Primeiramente, apresentam-se as abordagens de avaliação passíveis de aplicação a esses materiais, assim como suas definições e classificações. Em seguida, revisam-se conceitos de usabilidade em materiais didáticos digitais. Por fim, descreve-se uma série de instrumentos avaliativos passíveis de serem utilizados por professores.

\section{User-centred evaluation of digital learning materials: an investigation of instruments subject to use by teachers}

\section{ABSTRACT}

In this study, we discuss the importance of user-centered evaluation of digital learning materials. First of all, different evaluation approaches are introduced, as well as their definitions and classifications. Then, concepts of usability in digital learning materials are surveyed. Finally, a range of evaluation tools subject to use by teachers are described.

\section{KEYWORDS}

Evaluation tools, digital learning material. 


\section{INTRODUÇÃO}

Antes do início do ano letivo, os professores das escolas brasileiras são convocados para escolher o material didático impresso (livro didático) que será utilizado durante o ano. O processo de escolha do livro didático, para as escolas públicas, acontece através do PNLD (Programa Nacional do Livro Didático/MEC).

Os PCN (Parâmetros Curriculares Nacionais) recomendam que o livro didático não seja o único material utilizado pelo professor, propondo diretrizes e, a partir delas, boas situações de aprendizagem utilizando computadores. Entretanto, essas diretrizes não fazem menção a como os professores podem selecionar/avaliar material didático digital. Mais ainda, a rapidez da evolução das tecnologias desafia pesquisadores a estabelecer critérios que auxiliem o professor a escolher, classificar e avaliar materiais didáticos apresentados sob a forma digital.

Um trabalho de avaliação contínua centrada no usuário pode ser uma boa estratégia para assegurar a qualidade do material didático digital. Existem instrumentos oficiais (base científica) e não oficiais (base empírica) que estabelecem normas, critérios, recomendações e requisitos para avaliação da qualidade e usabilidade do material didático digital no processo de design (tanto no desenvolvimento do projeto quanto no do produto).

De acordo com Cybis (2003), o envolvimento do usuário pode trazer benefícios importantes para o design. $\mathrm{O}$ mesmo autor esclarece que existem três tipos básicos de envolvimento do usuário no processo de design:

- Informativo - o usuário como fonte de informações para o projeto através de entrevistas, questionários ou observações.

- Consultivo - o usuário é consultado sobre decisões de projeto, para que as verifique e emita opinião sobre elas. Essa consulta também pode ser realizada através de entrevistas, questionários e observações.

- Participativo - considerado o nível mais elevado de envolvimento do usuário no desenvolvimento do projeto, a responsabilidade pelo projeto é transferida a ele. Cabe ao designer recolher e tratar adequadamente os dados coletados através das técnicas possíveis.

Rocha e Baranauskas (2003) esclarecem que o design participativo caracteriza-se pelo envolvimento ativo dos usuários finais do sistema ao longo de todo o ciclo de design e desenvolvimento. Mais do que servir como fontes de informação, ou ser observados em sua rotina de trabalho, os usuários finais contribuem em todas as fases do ciclo, revelando suas perspectivas e necessidades.
No contexto de avaliação de materiais didáticos digitais, o professor participa como usuário direto e indireto. Considerado usuário direto na fase de planejamento de suas atividades, quando está selecionando/avaliando o software educativo; e usuário indireto na fase de aplicação, quando participa como um facilitador/mediador da interação alunos-software educativo.

Apesar do professor não ser o público alvo principal dos softwares educativos, ele julgará se o software é viável para utilização no contexto educacional utilizando instrumentos avaliativos.

Desta forma, entendemos que é importante identificar instrumentos avaliativos de material didático digital utilizáveis pelo usuário professor. Daí este artigo ter como finalidade discutir a importância da avaliação de materiais didáticos digitais. Primeiramente, apresentaremos as abordagens de avaliação. Em seguida, os instrumentos avaliativos passíveis de utilização por professores.

\section{ABORDAGENS DE AVALIAÇÃO NO CONTEXTO EDUCACIONAL}

Dix et al. (1998) esclarecem que a avaliação de um sistema tem três objetivos principais: avaliar a funcionalidade desse sistema; avaliar o efeito de sua interface sobre o usuário; e identificar algum problema específico com o sistema. Observa-se, assim, que a avaliação de materiais didáticos digitais deve acontecer de forma diferente e em momentos distintos. Desta forma, pode-se inferir que a avaliação de material didático digital é uma tarefa complexa e deve ser efetuada tanto na fase de desenvolvimento quanto na fase de utilização do software educativo.

Antes de enfocar especificamente as abordagens de avaliação no contexto educacional, é importante entender as interações que ocorrem nesse contexto, para então identificar as diversas situações de avaliação que ocorrem.

A partir das considerações de Anderson (2004) é possível identificar seis formas de interação em educação: aluno-aluno, aluno-professor, aluno-conteúdo, professor-professor, professor-conteúdo e conteúdo-conteúdo (Figura 1).

Interação aluno-aluno - vista como uma exigência na educação à distância, ou seja, a interação entre pares é crucial para o desenvolvimento de comunidades de aprendizagem, permitindo aos alunos desenvolverem habilidades interpessoais e compartilharem conhecimento como membros de uma comunidade.

Interação aluno-professor - é apoiada por uma grande variedade de formatos de aprendizagem, as quais incluem comunicação síncrona e assíncrona. 
Interação aluno-conteúdo - fornece novas oportunidades ao aluno, incluindo a imersão em microambientes, exercícios em laboratórios virtuais, desenvolvimento de conteúdos interativos, entre outras possibilidades.

Interação professor-professor - cria a oportunidade de desenvolvimento profissional, incentivando os professores a tirar vantagem da descoberta de novos conhecimentos em seus próprios assuntos e dentro da comunidade acadêmica.

Interação professor-conteúdo - o foco desta interação está na criação de conteúdos e atividades de aprendizagem por parte dos professores, permitindo a eles monitorar e atualizar continuamente os conteúdos das atividades que criaram para seus alunos.

Interação conteúdo-conteúdo - novo modo de interação educacional no qual o conteúdo está programado para interagir com outras fontes de informação automatizadas, de modo a atualizar-se constantemente a si próprio.

Acreditamos que ao modelo de Anderson (2004) podem-se associar as modalidades de avaliação passíveis de ocorrer em cada uma das interações (Figura 2).

Avaliação prognóstica - acontece na interação professor-conteúdo, considerada por Squires e Preece (1996) uma avaliação feita antes do uso do software educativo, ou seja, quando os professores estão fazendo seu planejamento.

Avaliação em grupo - está na interação professorprofessor, aluno-professor, aluno-aluno, ou seja, quando professores e/ou alunos estão juntos discutindo,

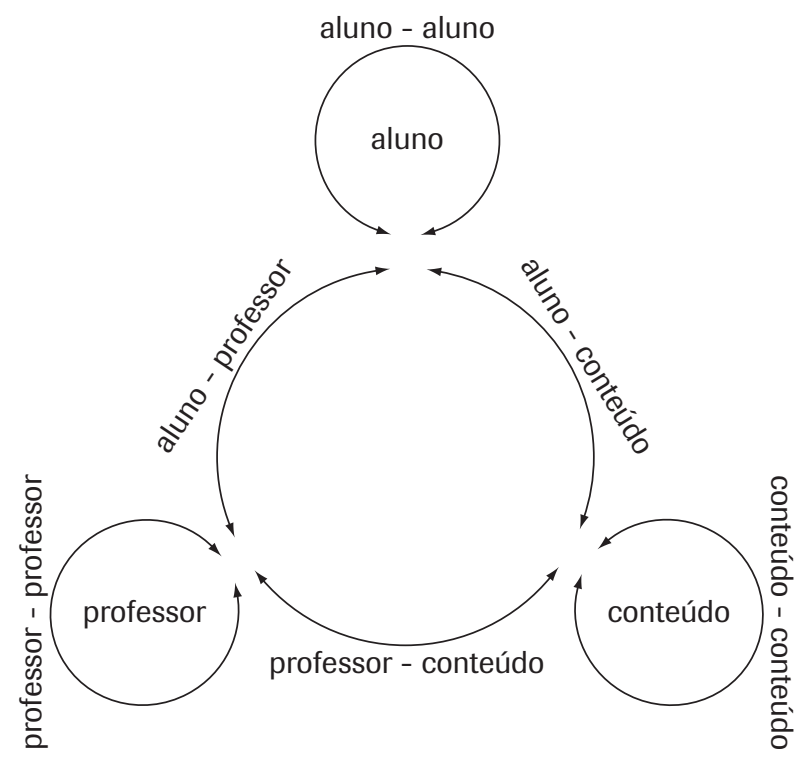

Figura 1: Formas de interação na educação à distância. Fonte: Anderson, 2004 avaliando ou tomando decisões a respeito do software que será utilizado.

Avaliação contextual - refere-se à interação professorprofessor, aluno-professor, aluno-aluno. Desta forma, este tipo de avaliação precisa necessariamente estar num contexto de uso, no qual aluno e professor discutem (juntos ou individualmente) sobre o software educativo.

Avaliação de codescoberta - ocorre durante a interação professor-professor, aluno-professor, aluno-aluno. De acordo com Anderson (2004), a teoria construtivista enfatiza a importância da interação em pares na investigação e no desenvolvimento de perspectivas múltiplas. Desta forma auxilia também professores e/ou alunos em suas relações interpessoais enquanto contribui na avaliação dos softwares educativos.

Avaliação interativa/participativa - enfatiza a interação professor-professor, aluno-professor, aluno-aluno, aluno-conteúdo, ou seja, permite aos alunos e/ou professores ter uma postura crítica e colaborativa diante dos conteúdos e participar ativamente do processo ensino-aprendizagem.

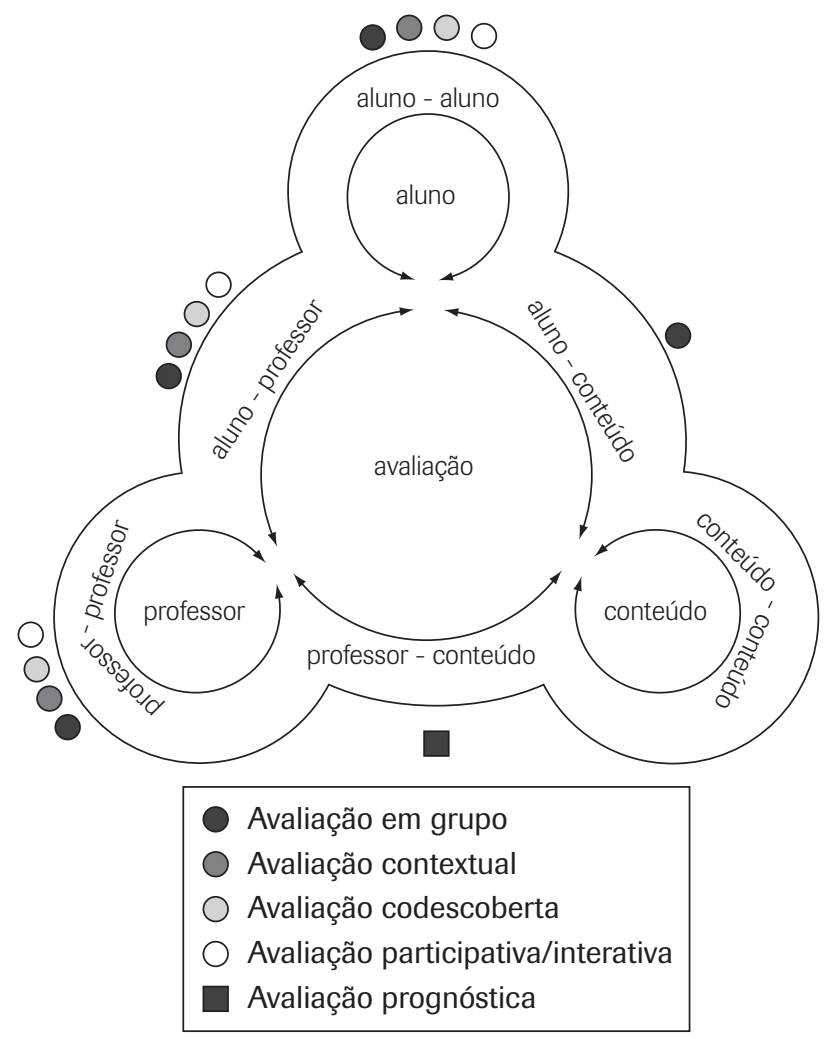

Figura 2: Formas de avaliação no contexto educacional. Fonte: com base em Anderson, 2004. 


\subsection{Critérios de avaliação de softwares educativos}

Autores de diversas áreas do conhecimento propõem uma série de critérios de diferentes naturezas. Neste tópico, optamos por apresentar os critérios identificados na literatura conforme as três categorias de critérios propostas por Silva (2002): ergonômicos, pedagógicos e comunicacionais. A Figura 3 sintetiza o conjunto de critérios priorizados neste artigo, os quais convergem para um único ponto: avaliação de material didático digital.

Critérios ergonômicos - asseguram que o usuário possa utilizar o software educativo com segurança, conforto e produtividade. Desta forma, são apresentadas a seguir a decomposição e breve definição dos critérios ergonômicos:

- Condução - meios disponíveis para orientar, informar e conduzir o usuário na interação com o computador (p. ex., mensagens, alarmes);

- Carga de trabalho - relaciona todos os elementos da interface que têm papel importante na redução da carga cognitiva e perceptiva do usuário e no aumento da eficiência do diálogo;

- Controle explícito do usuário - refere-se tanto ao processamento explícito das ações do usuário pelo sistema, quanto ao controle que este tem sobre o processamento de suas ações pelo sistema;

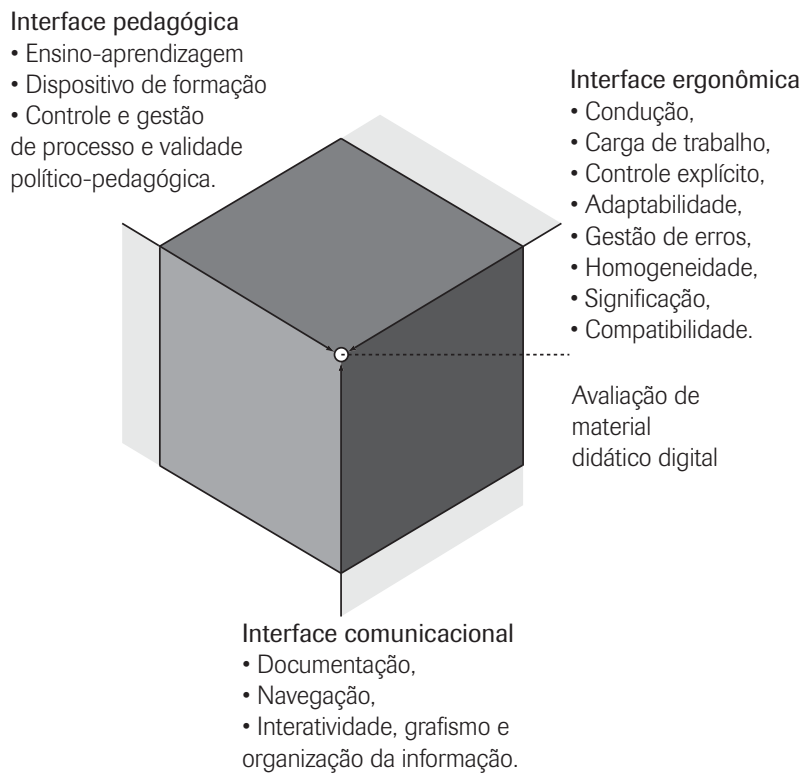

Figura 3. Categorias de critérios de avaliação de softwares educativos.

Fonte: com base em Silva, 2002
- Adaptabilidade - capacidade do sistema de reagir conforme o contexto, as necessidades e preferências do usuário;

- Gestão de erros - mecanismos que evitam ou reduzem a ocorrência de erros e, quando eles ocorrem, favorecem sua correção;

- Homogeneidade/coerência - forma como as escolhas, na concepção da interface (p. ex., códigos, denominações, formatos, procedimentos), são conservadas;

- Significado de códigos e denominações - diz respeito à adequação entre o objeto ou a informação apresentada ou pedida e sua referência;

- Compatibilidade - acordo entre as características do usuário (p. ex., memória, percepção, hábitos, competências, idade, expectativas), as tarefas e a organização das saídas, das entradas e do diálogo de uma dada aplicação. Diz respeito, ainda, ao grau de similaridade entre diferentes ambientes e aplicações.

Critérios pedagógicos - asseguram que as estratégias didáticas de apresentação das informações e tarefas cognitivas estejam em conformidade com o objetivo educacional e as características do usuário. A categoria critérios pedagógicos reúne um conjunto de quatro grandes grupos de critérios principais, cada um deles dividido em diferentes subcritérios.

- Critérios de ensino-aprendizagem - didáticos e de conteúdo (condução do aprendiz; estruturação do conteúdo; sistemas de ajuda; objetivos de aprendizagem; clareza dos conteúdos; validade do conteúdo); emocionais e afetivos (autonomia; motivação intrínseca/extrínseca; maturação/experiência); componente cognitiva (carga mental; experiência do aprendiz; estilos de aprendizagem);

- Critérios de dispositivos da formação - conformidade, aceitabilidade, compatibilidade, coerência;

- Critérios de controle e gestão do processo - componente prática, avaliação, tutoria;

- Critérios de validade político-pedagógica - pertinência, coerência, filosofia pedagógica.

Critérios comunicacionais - asseguram que os dispositivos midiáticos de comunicação sejam eficazes do ponto de vista da interatividade e da qualidade da informação. São critérios intermediários entre a tarefa e a ação.

- Documentação e material de apoio - informações referentes ao produto e suas condições de uso (p. ex., material impresso, manual on-line);

- Navegação - permite ao usuário saber onde onde ele está no ambiente do programa, aonde pode ir, como retornar, qual o caminho percorrido até então; 
- Interatividade - refere-se a grau de controle sobre o sistema no momento em que o aprendiz se depara com a possibilidade de tomar iniciativas partilhadas;

- Grafismo - habilidade da interface na comunicação ao usuário do funcionamento dos objetos gráficos que o guiam em sua interação;

- Organização das mensagens - equilíbrio de mensagens linguísticas e audiovisuais, favorecendo a construção das representações pertinentes.

\subsubsection{Usabilidade de material didático digital}

Squires e Preece (1996) ressaltam a importância de a avaliação de material didático digital levar em conta tanto a aprendizagem quanto a usabilidade, buscando a integração dos dois aspectos. Por isso, enfocamos de forma mais detalhada neste tópico a usabilidade de material didático digital.

De acordo com Jokela et al. (2003) a definição de usabilidade da ISO 9241-11 tornou-se a principal referência. Usabilidade é definida por essa norma como sendo a eficácia, a eficiência e a satisfação com que os usuários alcançam seu objetivo executando uma tarefa em determinado ambiente.

Alguns autores propuseram definições mais operacionais do termo, utilizando a avaliação de sistemas informatizados. Nesse sentido, Shackel (1991), por exemplo, propôs a seguinte definição operacional de usabilidade:

- Eficácia - uma gama especificada de tarefas deve ser cumprida por uma porcentagem especificada de usuários dentro de uma proporção determinada de ambientes de uso;

- Habilidade de aprendizado - as tarefas devem ser aprendidas pelo usuário do sistema dentro de um determinado tempo;

- Flexibilidade - o sistema deve ser passível de adaptação para algumas variações de tarefa e de ambientes não usuais;

- Atitude do usuário - a utilização do sistema deve ocorrer dentro de níveis aceitáveis de cansaço, desconforto, frustração e esforço do usuário; o atendimento aos usuários fará com que a utilização do sistema seja melhorada progressivamente, de modo a despertar entre esses usuários o desejo de utilizar o sistema.

Um outro exemplo de operacionalização é sugerido por Chapanis (1991):

- Fácil de abrir - tempo necessário para instalar e iniciar um sistema (programa instalado e funcionando);

- Fácil de aprender - tempo necessário para aprender como realizar um conjunto de tarefas;
- Desempenho - tempo suficiente para executar um conjunto especificado de tarefas;

- Contagem de erros - número de erros cometidos, ou tempo necessário para corrigir erros;

- Versatilidade ou funcionalidade - número de diferentes procedimentos que o sistema pode adotar;

- Avaliação geral - combinações de duas ou mais avaliações anteriores.

Por fim, Nielsen (1993) associa os seguintes atributos operacionais de usabilidade:

- Facilidade de aprendizagem - o sistema deve ser fácil de aprender, de modo que o usuário possa começar rapidamente algum trabalho;

- Eficiência - uma vez o usuário treinado, o sistema deve ser eficiente para ser utilizado de forma a atingir níveis de produtividade elevados na realização das tarefas;

- Facilidade de memorização - a operação do sistema deve ser fácil de lembrar, de forma que após um período de tempo sem utilizá-lo o usuário consiga retornar e realizar suas tarefas sem a necessidade de reaprender a interagir com ele;

- Baixa taxa de erros - o sistema deve ter um índice de erros baixo, de modo que os usuários realizem suas tarefas sem dificuldades, cometendo poucos erros durante sua utilização;

- Satisfação - o sistema deve ser agradável de usar, de forma que os usuários considerem satisfatória a sua utilização.

No contexto educacional, por exemplo, essas medidas de usabilidade de Shackel (1991), Chapanis (1991) e Nielsen (1993) seriam:

- Facilidade de aprendizado - ocorre quando o aluno consegue explorar o software educativo e realizar suas tarefas;

- Eficiência de uso - ocorre quando o aluno, tendo aprendido a interagir com o software educativo, consegue atingir níveis altos de produtividade na realização de suas tarefas;

- Facilidade de memorização - ocorre quando, após um período de tempo sem utilizar o software educativo, o aluno consegue retornar e realizar suas tarefas sem a necessidade de reaprender a interagir com ele;

- Baixa taxa de erros - ocorre quando o aluno realiza suas tarefas, no software educativo, sem maiores dificuldades ou constrangimentos e é capaz de recuperar erros, caso eles ocorram; 
- Satisfação subjetiva - ocorre quando o aluno considera agradável a utilização do software educativo e sente-se bem utilizando-o novamente.

\subsection{Instrumentos avaliativos de material didático digital}

Conforme verificado durante a revisão de literatura conduzida no desenvolvimento deste artigo, os instrumentos concebidos para a avaliação de materiais didáticos digitais podem ser classificados em: checklists, diretrizes, escalas de avaliação, formulários, questionários e sistemas (Tabela 1). Estes instrumentos podem ainda apresentar-se de forma híbrida, ou seja, utilizando agrupamentos de técnicas para identificação dos problemas de usabilidade.

A seguir apresentamos uma síntese das categorias dos instrumentos avaliativos direcionados para materiais didáticos digitais.

\subsubsection{Checklists}

São listas detalhadas de itens a serem checados na produção de eventos, procedimentos de segurança etc. Podem ser utilizadas para verificação, referência ou como auxílio na tomada de decisões (CAMBRIDGE INTERNATIONAL DICTIONARY OF ENGLISH, 1995).

As definições encontradas na área de Ergonomia também fazem referência às listas. Para Stanton (1998), checklist é a lista de itens que podem aparecer na forma de questões ou ações a serem realizadas. Podem apresentar um sistema de pontuação ou coletar comentários qualitativos. Para Cybis (2003), checklist também pode ser considerado uma lista de verificação através da qual profissionais, não necessariamente especialistas em ergonomia, diagnosticam problemas das interfaces.

Durante o desenvolvimento do presente trabalho identificaram-se os seguintes checklists para avaliação de softwares educativos:

\section{Tabela 1: Instrumentos direcionados para avaliação} de material didático digital

\begin{tabular}{lc}
\hline Categorias de instrumento & Quantidade \\
\hline Checklists & 4 \\
Diretrizes & 3 \\
Escala de avaliação & 1 \\
Formulários & 5 \\
Híbridos & 2 \\
Questionários & 2 \\
Sistemas & 5 \\
Total & 22 \\
\hline
\end{tabular}

CSEI - Children's Software Evaluation Instrument (BUCKLEITNER, 1998)

- O que é - ferramenta de avaliação usada para fazer toda a inspeção do sistema. As seis categorias ajudam a ter em mente o que é qualidade de software infantil. Este instrumento permite identificar se o software é fácil de usar, se é possível ser controlado pelas crianças, se o conteúdo educacional é sólido, se é divertido e se o design corresponde às expectativas do usuário.

- Quando se aplica - considerado um método de avaliação somativo, pode ser utilizado antes, durante e depois da utilização do software educativo.

- Por quem deve ser aplicado - deve ser utilizado por professores.

2002)

MAEP - Método de Avaliação Ergopedagógico (SILVA,

- O que é - instrumento interativo que serve como ferramenta de ajuda à avaliação ergopedagógica de PEIs (Produtos Educacionais Informatizados). Sua concepção é baseada na sistematização de um conjunto de critérios ergonômicos, pedagógicos e comunicacionais.

- Quando se aplica - aplica-se numa avaliação somativa e prognóstica, ou seja, recomenda-se que seja aplicado antes da utilização do software educativo. De acordo com Silva (2002), se os educadores possuem competência em relação a critérios de aprendizagem, o mesmo não ocorre em termos de usabilidade. Nesse contexto, é necessário dispor de uma ferramenta que lhes permita efetuar uma avaliação a priori do programa, de maneira que tenham uma orientação clara na identificação de como o dispositivo trata a aprendizagem e de como os usuários irão compreendê-lo e operá-lo, ou seja, tratase de avaliar a integração da usabilidade com o conteúdo e a forma de aprender.

- Por quem deve ser aplicado - sua aplicação foi pensada para ajudar profissionais de diferentes áreas (educação, designers, engenheiros, programadores e outros) na avaliação de PEIs.

PROINFO - Programa Nacional de Informática na Educação (PROINFO, 2007)

- O que é o instrumento - relatório apresentado no III Encontro Nacional do PROINFO proposto pelo MEC, contendo 20 perguntas que orientam o professor numa avaliação sobre software educativo.

- Quando se aplica - método somativo e prognóstico, devendo ser utilizado antes da utilização do software educativo em sala de aula. De acordo com o relatório, todo recurso utilizado em sala de aula (incluindo o software educativo) deve passar por análise prévia do professor. 
- Por quem deve ser aplicado - deve ser aplicado por professores.

TICESE - Técnica de Inspeção de Conformidade Ergonômica de Software Educacional (GAMEZ, 1998)

- O que é - segundo Gamez (1998), diferentemente de outras técnicas, a TICESE tem um enfoque particular sobre a ergonomia de software aplicada a produtos educacionais informatizados. De acordo com o autor, a técnica orienta o avaliador para a realização de inspeção de conformidade ergonômica do software. Desta forma, são considerados tanto os aspectos pedagógicos como os aspectos referentes à interface do produto.

- Quando se aplica - considerada uma técnica somativa (software já concluído), pode ser aplicada antes e durante a utilização do software educativo em sala de aula.

- Por quem deve ser aplicado sugere-se que a TICESE seja aplicada por avaliadores, preferencialmente uma equipe multidisciplinar, com alguma experiência na utilização de PEIs em ambiente escolar. O autor sugere também que na equipe de avaliação haja um profissional com conhecimentos em ergonomia de IHC (Interação Humano-Computador), tendo em vista o enfoque sobre a usabilidade.

\subsubsection{Diretrizes}

São conjuntos de instruções ou indicações para se levar a termo um plano ou uma ação. São informações com a intenção de orientar as pessoas sobre o que deve ser feito e como (PROCHTER, 1995).

Perry, Andrade Neto e Amaral (2005) esclarecem que, para a área de ergonomia, diretrizes são recomendações as quais cabe ao avaliador seguir, elas podem ser encontradas sob a forma de recomendações gerais ou tratando de algum item específico.

Durante o desenvolvimento deste trabalho identificaram-se alguns autores que propuseram diretrizes para conduzir o processo de avaliação de softwares educativos:

Cronje (1998) - processo de avaliação de software e seu efeito na aprendizagem.

- O que é - modelo de sistematização de projeto que envolve não apenas critérios da concepção mas também de avaliação em todas as etapas de desenvolvimento do projeto de softwares interativos.

- Quando se aplica - é um processo de avaliação de software envolvendo vários estágios, ou seja, desde o reconhecimento das necessidades da avaliação, passando pela avaliação formativa e avaliação somativa e finalizando com o impacto do software. Desta forma, entende-se que pode ser aplicado em softwares em desenvolvimento e já concluídos, e também antes, durante e depois da utilização do software educativo em sala de aula.

- Por quem deve ser aplicado - dependendo do estágio, pode ser aplicado por profissionais de diferentes áreas do conhecimento: educadores, pesquisadores, gerentes, programadores, designers, público alvo e outros.

Hanna, Risben e Alexander (1997) - diretrizes para teste de usabilidade com crianças.

- O que é - a aplicação do conjunto de diretrizes visa facilitar a realização de testes de usabilidade com crianças das seguintes faixas etárias: pré-escolares ( 2 a 5 anos); do ensino fundamental (6 a 10 anos); e do ensino fundamental e médio (11 a 14 anos).

- Quando se aplica - os autores defendem a idéia de envolver o usuário (criança) no processo de design, mas é possível também aplicar o instrumento ao uso de produtos já concluídos.

- Por quem deve ser aplicado - acredita-se que tanto na avaliação formativa quanto na somativa o avaliador (designers, desenvolvedores, psicólogos, pedagogos, professores e outros profissionais) precisa ter conhecimentos e experiência em usabilidade para poder aplicar o teste.

Squires e Preece (1999) - prognóstico de qualidade em software educacional.

- O que é - o objetivo de Squires e Preece (1999) é sugerir diretrizes de uma avaliação antecipada (prognóstico de avaliação) para professores, a qual tira partido de experiências anteriores, trazendo uma visão socioconstrutivista da aprendizagem. A abordagem dos autores é adaptar noções de "avaliação heurística" introduzidas por Molich e Nielsen (1990) como parte de um exercício de avaliação de usabilidade.

- Quandoseaplica-deacordocomSquiresePreece(1999), as heurísticas podem ser aplicadas somente como uma avaliação adiantada, ou seja, como um instrumento prognóstico de avaliação, antes da utilização no contexto educacional.

- Por quem deve ser aplicado - direcionado para professores. O propósito das heurísticas é encorajar os 
avaliadores a focarem sistematicamente todos os aspectos de design do software educacional. O processo da avaliação heurística requer que os professores revisem o software, o seu conhecimento de como deveriam apresentar o software a seus alunos e de como os alunos aprendem, assim o professor faz um julgamento do software pelos seus propósitos educacionais.

\subsubsection{Escalas de avaliação}

Segundo Lakatos e Marconi (2002), escala é um instrumento científico de observação e mensuração dos fenômenos sociais. É importante destacar que a escala de avaliação considerada nessa classificação pode ser comparada à escala de diferencial semântico, ou seja, o avaliador mostra a posição de sua atitude em relação ao objeto da pesquisa em uma escala na qual as extremidades são compostas por pares de adjetivos/frases bipolares. A aplicação das escalas de diferencial semântico para produtos diferentes permite a construção de gráficos de análise comparativos. Mattar (2001) lembra que se pode atribuir ou não valores numéricos a esse tipo de escala.

No desenvolvimento do trabalho identificou-se apenas uma obra que propõe a avaliação de software educativo utilizando-se de uma escala:

Reeves e Harmon (1996) - avaliação para multimídia educacional.

- O que é - Reeves e Harmon (1996) descrevem duas dimensões complementares para avaliar programas multimídia interativos para educação e treinamento. A primeira abordagem é baseada em um conjunto de 14 dimensões pedagógicas. A segunda é baseada em um conjunto de dez dimensões da utilização da interface. Os autores acreditam que explicações sobre dimensões pedagógicas e de interface de multimídia interativa podem beneficiar todas as partes envolvidas no design, reconhecimento e uso desses sistemas.

- Quando se aplica - considerado um método somativo, visto que o exemplo de aplicação do método tratado pelos autores é para softwares já concluídos. Deve ser aplicado antes da utilização do software educativo em sala de aula.

- Por quem deve ser aplicado - por ter dimensões pedagógicas como critério no método, acredita-se que a aplicação seja recomendada para professores, mas também para desenvolvedores.

\subsubsection{Formulários}

Janela ou documento que apresenta informações de forma diagramada e que possui campos para que o usuário possa introduzir ou modificar informações (NOVO DICIONÁRIO ELETRÔNICO AURÉLIO, 2004).

Conforme Cervo e Bervian (1996), o formulário é uma lista informal, catálogo ou inventário, destinado à coleta de dados resultantes de observações ou interrogações, cujo preenchimento é feito pelo próprio investigador. De acordo com SILVA (2005), o formulário é muito semelhante ao questionário. $\mathrm{O}$ que diferencia um do outro é o modo de aplicação. Enquanto o questionário é entregue para o informante responder sozinho, o formulário é preenchido pelo pesquisador, o qual pergunta e assinala as alternativas dadas pelo respondente.

Durante o desenvolvimento do trabalho, identificaram-se os seguintes formulários para avaliar softwares educativos:

ASE - Avaliação de Software Educativo - Ficha de Registro (VIEIRA, 1999)

- O que é o instrumento - o formulário ASE é uma sugestão para auxiliar os professores a registrarem suas observações sobre avaliação de um software de uso educacional, levando em consideração aspectos pedagógicos e técnicos.

- Quando se aplica - instrumento de avaliação somativa e prognóstica. Deve ser aplicado antes da utilização do software educativo em sala de aula.

- Por quem deve ser aplicado - o formulário deve ser utilizado por professores.

ESEF - Educational Software Evaluation Form (ISTE, 2002)

- O que é o instrumento - o objetivo deste formulário é fornecer aos professores um guia de avaliação focado no uso educacional do meio tecnológico. Este formulário pode ser usado para software, site, CR-ROM ou qualquer outro meio baseado em tecnologia para ser usado com estudantes.

- Quando se aplica - avaliação somativa. Deve ser aplicada antes da utilização do software educativo em sala de aula.

- Por quem deve ser aplicado - o formulário deve ser aplicado por professores.

PCEM - Plantilla para la Catalogación y Evaluación Multimedia (GRAELLS, 2001)

- O que é o instrumento - o formulário está estruturado em três partes: identificação do contexto; avaliação dos aspectos técnicos, pedagógicos e funcionais; quadro de avaliação geral.

- Quando se aplica - instrumento de avaliação somativa, pode ser usado antes da aplicação do software educativo no contexto educacional. 
- Por quem deve ser aplicado - direcionado para professores.

SEF - Software Evaluation Form (SCHROCK, 2000)

- O que é o instrumento - segundo o autor, o formulário SEF foi criado para abranger os aspectos mais usados pelo professor no momento da escolha de um software educativo.

- Quando se aplica - instrumento de avaliação somativa, pode ser usado antes da aplicação do software educativo em sala de aula.

- Por quem deve ser aplicado - direcionado para professores.

SK - SuperKids - Sample Teacher Review Form

(SuperKids Educational Software Review, 1998)

- O que é o instrumento - desenvolvido para atender professores no contexto educacional, não para ser utilizado em condições de laboratório. O objetivo do formulário

\section{o contexto de avaliação de materiais didáticos digitais, o professor participa como usuário direto e} indireto.

é trazer o avaliador (professor) o mais perto possível do ambiente real em que os softwares educativos são utilizados.

- Quando se aplica - instrumento de avaliação somativa, pode ser usado antes da aplicação do software educativo no contexto educacional.

- Por quem deve ser aplicado - direcionado para professores.

\subsubsection{Híbridos}

Consideramos como instrumentos avaliativos híbridos os agrupamentos de técnicas diferentes para identificação dos problemas de usabilidade.

No desenvolvimento deste trabalho identificaram-se os seguintes instrumentos avaliativos híbridos para avaliar softwares educativos:

MAQSE - Metodologia para Avaliação da Qualidade de Software Educacional (CAMPOS, 1994)

- O que é o instrumento - metodologia para avaliação da qualidade do software educacional em duas fases: (a) desenvolvimento e (b) utilização do produto.

- Quando se aplica - o Manual para Avaliação da Qualidade de Software Educacional oferece subsídios para a definição da qualidade durante o processo de desenvolvimento do software educacional e na seleção de um produto de software disponível no mercado, ou seja, recomenda-se a utilização antes da utilização em sala de aula.

- Por quem deve ser aplicado - o autor esclarece que o Manual para Avaliação da Qualidade de Software Educacional tem como objetivo orientar os desenvolvedores de software e os usuários (professores, alunos e mantenedores), que, criticamente, poderão selecionar o software adequado a seus propósitos.

MAQSEI - Metodologia de Avaliação de Qualidade de Software Educacional Infantil (ATAYDE, 2003)

- O que é o instrumento - segundo o autor, a Metodologia de Avaliação de Qualidade de Software Educacional Infantil denominada MAQSEI fundamenta-se em um conjunto de heurísticas, abrangendo aspectos pedagógicos e técnicos do programa. $\mathrm{Ou}$ seja, inclui tanto os aspectos da usabilidade quanto de ensinoaprendizagem.

- Quando se aplica - de acordo com Atayde (2003), a metodologia e as heurísticas podem ser utilizadas em avaliações formativas, colaborando para que o desenvolvimento descubra defeitos e modificações necessárias no programa, ou em avaliações somativas, como ferramenta de apoio a escolas, pais ou interessados na escolha do software educacional infantil a ser utilizado pelas crianças. Recomenda-se que seja utilizado antes e durante a utilização em sala de aula.

- Por quem deve ser aplicado - pode ser usada por profissionais da área de educação, informática e afins que desejem avaliar a qualidade de software educacional infantil. Os testes devem ser aplicados por profissionais mas o software deve estar sendo utilizado por crianças.

\subsubsection{Questionários}

Questionário é uma série de questões ou perguntas, um interrogatório (NOVO DICIONÁRIO ELETRÔNICO AURÉLIO, 2004). ParaSilva (2005) e Marconi L Lakatos (2002), questionário é um instrumento de coleta de dados constituído por uma relação de perguntas que o entrevistado responde sozinho, assinalando ou escrevendo as respostas.

$\mathrm{Na}$ literatura da ergonomia, Hom (1998) acrescenta que os questionários são listas de questões distribuídas aos usuários, exigindo mais esforço por parte deles, pois é necessário que preencham o questionário e o devolvam ao pesquisador. 
Durante o desenvolvimento do trabalho, identificaramse os seguintes questionários para avaliação de softwares educativos:

IAQSEM - Instrumento de Avaliação da Qualidade para Software Educacional de Matemática (GLADCHEFF, 2001)

- O que é o instrumento - o objetivo de Gladcheff (2001) foi propor uma ferramenta de avaliação na forma de questionários, baseando-se tanto em aspectos técnicos como em conceitos e princípios de qualidade de software ligados à educação. A autora procurou neste questionário envolver isoladamente produtos de software direcionados ao aprendizado de matemática para alunos do ensino fundamental. Procurou, também, enfocar aspectos específicos para diferentes tipos de software educacionais (tutorial, exercício e prática, jogo pedagógico, simulação e sistema hipermídia). maior preparação dos professores para a análise crítica, avaliação e utilização de produtos multimídia.

- Quando se aplica - aplica-se a softwares educativos já concluídos, antes da sua utilização em sala de aula.

- Por quem deve ser aplicado - a avaliação concentra-se nos professores por trazer questões pedagógicas, entretanto percebe-se que pode ser utilizado por profissionais de outras áreas do conhecimento.

\subsubsection{Sistemas}

Sistemas são programas destinados a realizar funções específicas. A partir dessa definição, consideramos os sistemas como ferramentas multimídia para avaliação de produtos educativos com o propósito de auxiliar o usuário no processo da avaliação qualitativa e seleção de software educacional. Geralmente são disponibilizados através de CD-ROMs ou pela web, podendo apresentar perguntas abertas e fechadas.

No decorrer deste trabalho, quires e Preece (1996) ressaltam a importância da avaliação de material didático digital levar em conta

\section{tanto a aprendizagem quanto a usabilidade} identificaram-se os seguintes sistemas para avaliação de softwares educativos:

CASE - Comunidade de Análise de Software Educativo (LYRA et al., 2003)

- Como funciona o sistema - o CASE permite a criação de um ponto de encontro para uma comunidade de profissionais (educadores e designers) interessados na análise (classificação e avaliação) e design de softwares educativos. Esses profissionais poderão apreciar e analisar avaliações de diversos softwares educativos.

- Quando se aplica - a softwares já concluídos, pode ser utilizado antes, durante e depois no contexto educacional. Um usuário cadastrado no sistema poderá fazer o cadastramento de um software educativo relevante. Esse software é cadastrado pela informação da URL na qual ele se encontra disponível. Após o cadastro, o mesmo ficará disponível para consultas e posteriores análises (classificação, avaliação e relatos de experiência de qualquer usuário).

- Por quem deve ser aplicado - designers e professores. De acordo com Lyra et al. (2003), o ambiente poderá atrair tanto professores como designers de software. Os primeiros relatando experiências próprias e adquirindo as de colegas; os segundos observando a forma de uso e a análise crítica de profissionais que usam esse material para informar-se e produzir melhores aplicações.

MEMI - Méthode pour l'Évaluation de Multimedia Interactive (HÛ; CROZAT; TRIGANO, 2001)

- Como funciona o sistema - instrumento de avaliação de aplicações multimídia cujo princípio consiste em obter a opinião subjetiva de usuários não especialistas sobre 
as características das interfaces. O objetivo do instrumento é encontrar um equilíbrio entre a avaliação, considerando os dados objetivos e aqueles orientados para os critérios subjetivos.

- Quando se aplica - acredita-se ser uma avaliação somativa devido ao detalhe de obter a opinião subjetiva dos usuários não especialistas sobre as características das interfaces. Desta forma, deve ser utilizado antes e durante a aplicação do software em sala de aula.

- Por quem deve ser aplicado - segundo Silva (2002), o público alvo é o professor não especialista ou qualquer pessoa que deseje aprender a avaliar.

MEDA - Sistema Multimídia para Avaliação de Produtos Educativos (MEDA, 2002)

- Como funciona o sistema - o MEDA 97 é um sistema multimídia de ajuda à avaliação de produtos educativos. Permite a cada avaliador (projetista, difusor, usuário/ professor) construir uma grade de avaliação adaptada às necessidades de averiguação identificadas por cada um.

- Quando se aplica - pode ser utilizado na avaliação somativa e formativa assim como antes, durante e depois da aplicação do software educativo em sala de aula. De acordo com Silva (2002), os resultados são produtivos para as práticas de concepção, de utilização e de difusão do produto, elementos constitutivos dos polos de interesse para a realização de avaliação.

- Por quem deve ser aplicado - professores, especialistas em conteúdo, especialistas em comunicação, avaliadores, diretores de centros de recursos, responsáveis institucionais, consultores, produtores, distribuidores, diretores de marketing, designers, programadores.

SASE - Sistema de apoio à avaliação de software educacional (BEAUFOND; CLUNIE, 2000)

- Como funciona o sistema - tem o propósito de auxiliar o usuário no processo de avaliação da qualidade para a seleção de software educacional que será incorporado à escola.

- Quando se aplica - pode ser utilizado na avaliação somativa e formativa. E está direcionado para a utilização antes da aplicação do software educativo em sala de aula.

- Por quem deve ser aplicado - a ferramenta visa ajudar professores e equipe pedagógica de instituições de ensino na avaliação e seleção dos diversos produtos de software educacional (tutoriais, exercícios e práticas, simulações, jogos e sites na web) que conformarão o acervo escolar considerando quatro visões: a do professor ou especialista de conteúdo, a do orientador pedagógico, a do especialista em comunicação visual e a do especialista em informática.
SOFTMAT - Repositório de softwares para matemática do ensino médio (BATISTA, 2004)

- Como funciona o sistema - o SOFTMAT é um repositório de softwares cujo intuito é contribuir para o trabalho dos professores, incentivando atitudes mais abertas e ao mesmo tempo mais conscientes e críticas com relação à utilização das TIC em educação.

- Quando se aplica - método de avaliação somativo direcionado para a utilização antes da aplicação do software educativo em sala de aula.

- Por quem deve ser aplicado - professores de matemática do ensino médio.

\section{DISCUSSÃO}

De modo geral, os instrumentos avaliativos podem ser empregados em três ciclos do processo de design: no projeto propriamente dito (no qual, p. ex., o designer está

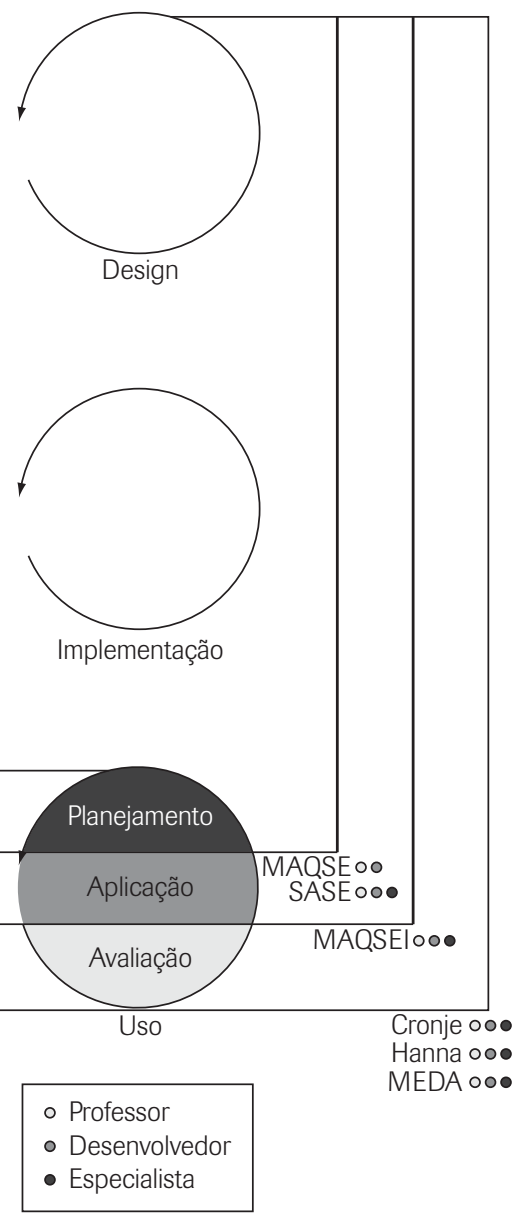

Figura 4: Instrumentos avaliativos utilizados no processo de design e utilização do material didático digital 
trabalhando no desenvolvimento de um software educativo de acordo com recomendações ergonômicas), na implementação (na qual, p. ex., o designer precisa de instrumentos avaliativos capazes de avaliar softwares na fase de implementação, ou seja, no desenvolvimento das especificações finais do produto/sistema) e na utilização (p. ex., desenvolvimento de mecanismos de teste com usuários, neste caso específico envolve o planejamento, a aplicação e avaliação realizada na prática docente do usuário professor).

Zabala (1998) explica que esses estágios estão fortemente interrelacionados, constituindo as unidades nomeadas pelo autor como planejamento, aplicação e avaliação. $\mathrm{O}$ autor afirma ser preciso entender que a prática não pode se reduzir ao momento em que se reproduzem os processos educacionais de aula, ou seja, a intervenção pedagógica tem um antes, um durante e um depois.

A unidade de planejamento no contexto educacional caracteriza-se pela preparação antecipada de um conjunto de ações, as quais serão aplicadas pelo professor em sala de aula, tendo em vista atingir determinados objetivos. A unidade de aplicação, por sua vez, visa a execução na prática do planejamento estabelecido pelo professor. E, por fim, a unidade de avaliação da aprendizagem, que pode ser considerada um processo contínuo e sistemático, realiza-se em função dos objetivos propostos no planejamento. De acordo com Zabala (1998), o planejamento e a avaliação dos processos educacionais são atividades indissociáveis da atuação docente.
Vale ressaltar que o foco deste trabalho não está na avaliação da aprendizagem mas no processo de escolha de instrumentos avaliativos/critérios de avaliação do material didático digital, a qual ocorre na unidade de planejamento.

Com base no estudo descritivo realizado, verificamos que os 22 instrumentos contemplam a fase de utilização do produto. Desses 22, 16 estão concentrados na fase de utilização do produto e somente 6 podem ser utilizados em todo o processo de design (Figura 4).

\section{CONCLUSÕES E DESDOBRAMENTOS}

O objetivo deste estudo foi discutir a importância da avaliação de materiais didáticos digitais apresentando as abordagens de avaliação aplicada a esses materiais, assim como mostrar os instrumentos avaliativos passíveis de utilização por professores.

Com base nesse estudo descritivo, os desdobramentos dessa pesquisa envolvem, em um primeiro momento escolher e testar instrumentos de avaliação com professores de áreas distintas. Com base nesses resultados, objetiva-se, em um segundo e último momento, propor diretrizes para avaliação de material didático digital, tendo em vista professores do ensino fundamental e médio.

\section{Artigo recebido em 23/01/2009 Aprovado para publicação em 28/06/2009}

\section{REFERÊNCIAS}

ANDERSON, T. Toward a Theory of Online Learning. Theory and Practice of Online Learning. Canadá: Athabasca University, 2004. Disponivel em: <http://cde.athabascau.ca/online_book/ch2. html $>$ Acesso em: agosto 2007.

ATAYDE, A. P. R. Metodologia de avaliação de qualidade de software educacional infantil - MAQSEI. Belo Horizonte, 2003. 250 f. Dissertação (Mestrado em Ciência da Computação) - Universidade Federal de Minas Gerais.

BATISTA, S. C. F. Softmat: um repositório de softwares para matemática do ensino média - um instrumento em prol de posturas mais conscientes na seleção de softwares educacionais. Campos Goytacazes, 2004. 202 f. Dissertação (Mestrado em Engenharia de Produção) - Centro de Ciência e Tecnologia, Universidade Estadual do Norte Fluminense.
BEAUFOND, C. E. C.; CLUNIE, G. T. SASE: uma ferramenta de apoio à avaliação de software educacional. In: CONGRESSO IBEROAMERICANO DE INFORMÁICA EDUCATIVA, 5, 2000, Chile. Anais eletrônicos... Disponível em: <http://www.c5.cl/ ieinvestiga/actas/ribie2000/>. Acesso em: março 2007.

BUCKLEITNER, W. Children's Software Evaluation Instrument. 1998. Disponível em: <http://www. childrenssoftware.com/rating.html $>$ Acesso em: novembro 2007

CAMPOS, G. H. B. Metodologia para avaliação da qualidade de software educacional. Diretrizes para desenvolvedores e usuários. Rio de Janeiro, 1994. 232 f. Tese (Doutorado em Engenharia de Produção) - Universidade Federal do Rio de Janeiro.

CERVO, A. L.; BERVIAN, P. A. Metodologia Cientifica. 4 ed. São Paulo: Makron Books, 1996.
CHAPANIS, A. Evaluating usability. In: SHACKEL, B.; RICHARDSON, S. Human factors for informatics usability. Cambridge: Cambridge University Press, 1991. p. 359-395.

COSTA, F. Pedactice: educational multimedia in school. 1999. Disponível em: <http://www. fpce.ul.pt/projectos/pedactice $>$ Acesso em: junho 2007.

CRONJE, J. The process of evaluating software and its effect on learning. Pretoria: Department of Didactics, University of Pretoria, 1998. Disponivel em: <http://hagar.up.ac.za/catts/learner/eel/ Conc/conceot.htm>. Acesso em: abril 2007.

CYBIS, W. A. Engenharia de usabilidade: uma abordagem ergonômica. Florianópolis: Laboratório de Utilizabilidade de Informática/UFSC, 2003.

DIX, A. et al. Human-Computer Interaction. London: Prentice Hall, 1998. 
GAMEZ, L. TICESE: técnica de inspeção de conformidade ergonômica de software educacional. Manual do avaliador. Porto, 1998. $45 \mathrm{f}$. Dissertação (Mestrado em Engenharia Humana) - Universidade do Minho. (Parte da Dissertação)

GLADCHEFF, A. P. Um instrumento de avaliação da qualidade para software educacional para software educacional de matemática. São Paulo, 2001. 212 f. Dissertação (Mestrado em Ciência da Computação) - Instituto de Matemática e Estatística, Universidade de São Paulo.

GRAELLS, P. M. Ficha de Catalogación y Evaluación Multimedia. 2001. Disponível em: <http://dewey. uab.es/pmarques/dim/revistadigital/dimavam0. rtP Acesso em: setembro 2007.

HANNA, L.; RISBEN, K.; ALEXANDER, K. Guidelines for usability testing with children. Interactions, v. 4, n. 5, p. 9-14, set./out. 1997.

HOM, J. The usability methods toolbox handbook. 1998. Disponível em: <http://jthom.best.vwh.net/ usability/> Acesso em: maio 2007.

HÛ, O.; CROZAT, S.; TRIGANO, P. E.M.P.I.: Une méthode pour l'évaluation de multimedia interactive pédagogique. Sciences et techniques éducatives, v. 8, n. 3-4, 2001.

International Society for Technology in Education - ISTE. Educational Software Evaluation Form. 2002. Disponível em: <http://cnets.iste.org/teachers/ web/t_form_software-eval.html> Acesso em: abril 2007.

JOKELA, T. et al. The standard of user-centered design and the standard definition of usability: analyzing ISO 13407 against ISO 9241-11. In: LATIN AMERICAN CONFERENCE ON HUMANCOMPUTER INTERACTION, 1, 2003, Rio de Janeiro. Anais... Rio de Janeiro: PUC - Rio, 2003. p. 53-60.

LAKATOS, E. M.; MARCONI, M. A. Fundamentos de metodologia científica. São Paulo: Atlas, 1993.
LYRA, A. et al. Ambiente virtual para análise de software educativo. In: WIE 2003 WORKSHOP BRASILEIRO DE INFORMÁTICA EDUCATIVA, 23, 2003, Campinas. Anais... Campinas: SBC, 2003. v. V, p. 227-238.

MATTAR, F. N. Pesquisa de marketing. 3 ed. São Paulo: Atlas, 2001.

MEDA-Média Screen CR-ROM, Université de Liége. 1997. In: SILVA, C. R. O. MAEP: um método ergopedagógico interativo de avaliação para produtos educacionais informatizados. Florianópolis, 2002. 224 f. Tese (Doutorado em Engenharia de Produção) - Universidade Federal de Santa Catarina.

NIELSEN, J. Usability engineering. San Diego, USA: Academic Press, 1993.

NOVO Dicionário Eletrônico Aurélio. Curitiba: Editora Positivo, 2004.

PERRY, G. T.; ANDRADE NETO, A. S.; AMARAL, F. G. Integrado conhecimentos, aproximando disciplinas: a importância do design e da ergonomia no projeto e no desenvolvimento de softwares educacionais. Revista Novas Tecnologias na Educação, v. 3, n. 1, maio 2005.

PROCHTER, P. Cambridge International Dictionary of English. Cambridge: Cambridge University Press, 1995.

PROGRAMA NACIONAL DE INFORMÁTICA NA EDUCAÇÃO - PROINFO. Checklist. In: ENCONTRO NACIONAL DO PROINFO, 3, 1998, Pirenópolis. Disponível em: < http://www2.uel.br/ seed/nte/analisedesoftwares.html $>$ Acesso em: outubro 2007.

REEVES, T. C.; HARMON, S. W. Systematic evaluation procedures for interactive multimedia for education and training. In: REISMAN, S. Multimedia Computing: preparing for the 21st Century. Hershey, PA: Idea Group Publishing, 1996. p. $472-582$.

ROCHA, H. da; BARANAUSKAS, M. C. Design $e$ avaliação de interfaces humano-computador. Campinas, SP: NIED/Unicamp, 2003.
SCHROCK, K. Software evaluation form. 2000. Disponível em: < http://courses.csusm. edu/educ $422 \mathrm{dh} /$ wordfiles/Software $\% 20$ Evaluation\%20Form.doc $>$ Acesso em: outubro 2007.

SHACKEL, B. Usability - context, framework, definition, design and evaluation. In: SHACKEL, B.; RICHARDSON, S. Human factors for informatics usability. Cambridge: Cambridge University Press, 1991. p. 21-37.

SILVA, C. R. O. MAEP: um método ergopedagógico interativo de avaliação para produtos educacionais informatizados. Florianópolis, 2002. $224 \mathrm{f}$ Tese (Doutorado em Engenharia de Produção) Universidade Federal de Santa Catarina.

SILVA, M. A. F da. Métodos e Técnicas de Pesquisa. Curitiba: Ibpex, 2005.

SQUIRES, D.; PREECE, J. Usability and learning: evaluating the potential of educational software. Computer and Education, v. 27, n. 1, p. 15-22, 1996.

SQUIRES, D.; PREECE, J. Predicting quality in educational software: evaluating for learning, usability and synergy between them. Interacting with Computers, v. 11 , n. 5 , p. 467-483, maio 1999.

STANTON, N. Human factors in consumer products. London: Taylor \& Francis, 1998.

Superkids Educacional Software Review. 1998. Disponivel em: < http://www.superkids.com/ aweb/pages/reviews/teacher.html $>$ Acesso em: outubro 2007.

VIEIRA, F. M. S. Avaliação de software educativo: reflexões para uma análise criteriosa. 1999. Disponível em: <http://www.edutecnet.com.br/ Textos/Alia/MISC/edmagali2.htm>. Acesso em: março 2007.

ZABALA, A. A prática educativa: como ensinar. Porto Alegre: Artmed, 1998.

\section{SOBRE OS AUTORES}

\section{Katia Alexandra de Godoi}

Universidade Federal do Paraná - UFPR

Curitiba - PR, Brasil

e-mail: kategodoi@hotmail.com

\section{Stephania Padovani}

Universidade Federal do Paraná - UFPR

Curitiba - PR, Brasil

e-mail: s_padovani2@yahoo.co.uk 